\title{
Clinical Reasoning: A 48-Year-Old Man Presenting With Diplopia
}

Niranjan K. Pehere, DNB, FICO (Hon), and Kebede Gofer, MD

Correspondence

Dr. Pehere

niranjan@lvpei.org

\section{MORE ONLINE}

O Video

A 48-year-old man, recently diagnosed with systemic hypertension, presented with suddenonset double vision for 4 days, which was relieved by closing one eye. On general examination, he was well-oriented in time, place, and person. His motor and sensory system examination was normal. Cranial nerves V, VII, and VIII were normal and there were no clinical signs of cerebellar dysfunction.

The ocular examination results are shown in figure $1, \mathrm{~A}$ and $\mathrm{B}$.

\section{Questions for Consideration:}

1. What is the relevance of knowing if the diplopia was binocular or uniocular?

2. Describe the ocular examination findings in figure $1, \mathrm{~A}$ and $\mathrm{B}$.

GO TO SECTION 2 

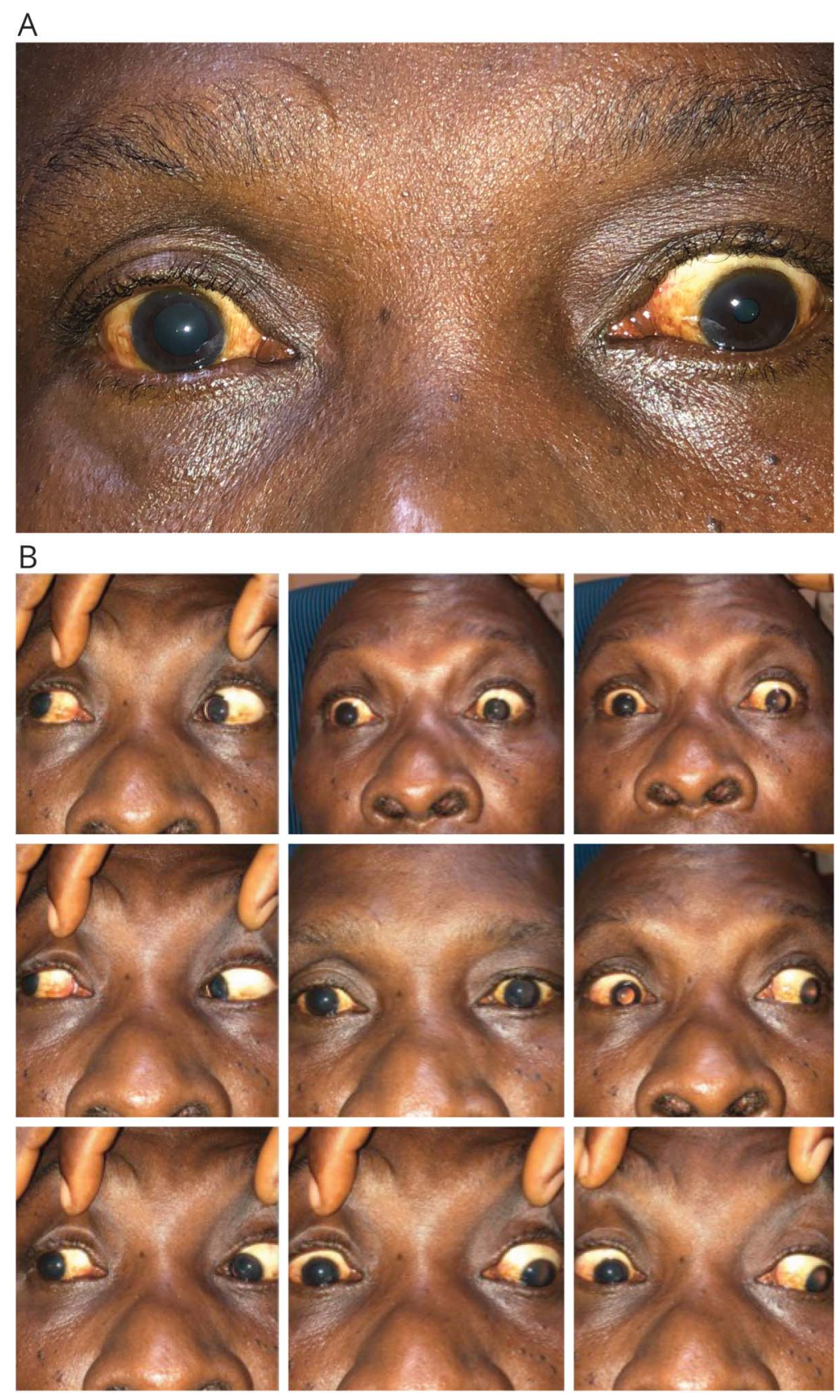

(A) Ocular alignment. (B) Ocular motility.

\section{Section 2}

The patient in this vignette presented with binocular diplopia (relieved by closing one eye), meaning that the diplopia was related to an ocular motility issue. Uniocular diplopia (persisting after closing one eye) points towards some problem in that eye like irregular refractive media (keratoconus, lenticonus, early cataract) and the patient needs a detailed ocular examination. ${ }^{1}$

As seen in figure 1A, there is upper eyelid retraction in both eyes (left > right) and gross anisocoria (right pupil $7 \mathrm{~mm}$ and left pupil $3 \mathrm{~mm}$ ). The right pupil did not react to direct or consensual light reactions and on attempted convergence. The left eye is grossly hypotropic by 20 prism diopters (figure 1A). There is complete upgaze palsy in both eyes, asymmetric downgaze palsy (right eye > left eye), and slight limitation of adduction in right eye (figure $1 \mathrm{~B}$ ).

In addition to the findings shown in figure $1, A$ and $B$, the patient had other oculomotor abnormalities. He was unable to converge his eyes and there was no convergence-retraction nystagmus on attempted upgaze. The doll's head maneuver failed to elicit any eye movements. There was a low-amplitude 
and low-frequency horizontal jerk nystagmus, right-beating on right gaze and left-beating on left gaze. There was also downbeating nystagmus of moderate amplitude and low frequency, increasing on downgaze. It was seen more prominently in the left eye since there was complete vertical gaze palsy in the right eye. There was also a torsional component to the nystagmus to the left (video 1).
Questions for Consideration:

1. What is the importance of performing the doll's head maneuver in such cases?

2. What is this typical pattern of oculomotor abnormality called?

3. What could be the site of lesion causing these oculomotor manifestations and the possible causes? 


\section{Section 3}

While evaluating gaze palsy, one should check the doll's head maneuver to differentiate between supranuclear vs nuclear/ infranuclear lesions. The doll's head manoeuver involves rotating the patient's head horizontally and vertically with eyelids open, and the patient looking at a target object. This test evaluates integrity of the vestibulo-ocular reflex (VOR), which causes eye movement by stimulating the ocular motor nuclei in brainstem to reflexively stabilize the eyes without involvement of the cerebral cortex. In a patient with horizontal or vertical gaze palsy, the presence of eye movements with doll's head maneuver indicates that the nuclear and infranuclear pathways are intact and the lesion is at supranuclear level. Absence of eye movement on doll's head maneuver is suggestive of a nuclear or infranuclear lesion, as in our patient. ${ }^{2}$ Since our patient has vertical gaze palsy with a negative doll's head maneuver, the site of lesion is likely to be at the thalamo-mesencephalic junction, which hosts the vertical gaze center.

Rostral interstitial nucleus of medial longitudinal fasciculus (riMLF) controls ipsilateral downward and contralateral upward gaze, hence an isolated unilateral lesion of riMLF would lead to impaired upgaze in contralateral eye and impaired downgaze in the ipsilateral eye. Fibers controlling contralateral upward gaze cross over at the posterior commissure (PC), hence a single lesion at the PC would cause bilateral upgaze palsy. A lesion affecting the PC and riMLF on one side would result in complete vertical gaze palsy in one eye and upgaze palsy in the other eye, and this combination is called vertical one and a half syndrome. ${ }^{3}$ Our patient had a complete vertical gaze palsy in the right eye and upgaze palsy in the left eye, most likely caused by the thalamo-mesencephalic infarct affecting the PC and right-sided riMLF. The other differential diagnosis for the hypotropia in the left eye could be skew deviation in right eye with hypotropia in the left eye, but on fundus examination there was no torsion in either eye and there was no reduction in hypotropia in supine position, thus ruling out skew deviation. ${ }^{4}$

\section{Questions for Consideration:}

This patient is being managed in a resource-limited setting in sub-Saharan Africa, where only CT scan is available.

1. Can you describe the lesion seen on the CT scan of the brain in this patient?

2. Can you explain the oculomotor, eyelid, and pupillary findings based on the CT scan?

GO TO SECTION 4 

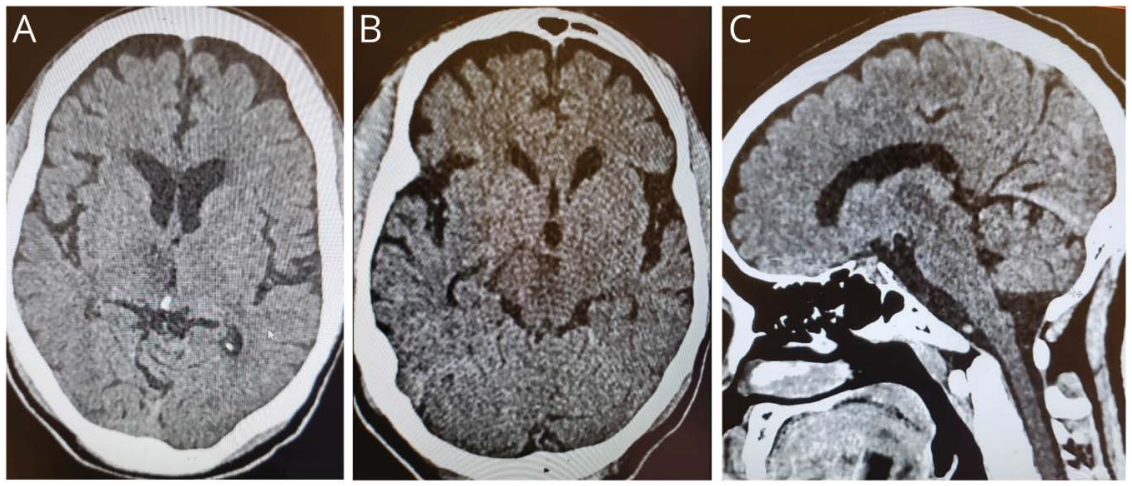

(A) Axial section. Note hypodensity in medial part of right thalamus. (B) Axial section at the level of quadrigeminal cistern. Note the caudal extension of the infarct into the midbrain. (C) Sagittal section. Note hypodensity involving thalamus extending into rostral part of midbrain on right side.

\section{Section 4}

CT scan of the head shows a focal hypodensity in the right thalamus, suggestive of infarction, involving its medial part close to the wall of the third ventricle, as seen in axial section (figure 2A), with extension into the rostral part of the midbrain, as seen in the axial section at the level of quadrigeminal cistern (figure 2B) and also in the sagittal section (figure 2C).

To explain all the oculomotor features of this case, a brief revision of control of vertical eye movements would help (figure $3 \mathrm{~A}){ }^{5}$ The final common pathway for vertical eye movements is formed by the oculomotor nucleus complex situated in the dorsal midbrain at the level of the superior colliculi (subnuclei of the superior rectus, inferior rectus, and inferior oblique) and trochlear nerve nuclei (supplying superior oblique muscle) situated in the dorsal midbrain at the level of the inferior colliculi. The vertical gaze center controlling the vertical eye movements is situated at the thalamomesencephalic junction and it comprises 3 principal structures: riMLF, interstitial nucleus of Cajal (INC), and PC. ${ }^{5}$

Table 1 summarizes details of the location, connections, functions, and clinical manifestations of lesions at these centers.

In a unilateral INC lesion associated with riMLF, torsional eye movement either does not have a fast component or is directed to the opposite side. Thus a combined involvement of

Figure 3 Schematic Diagram of Vertical Gaze Centers

A

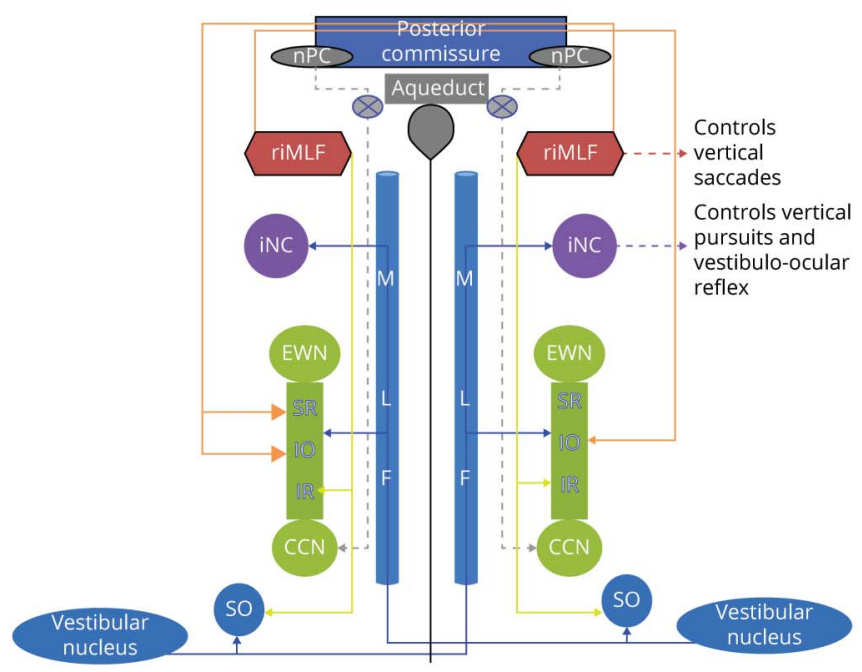

B

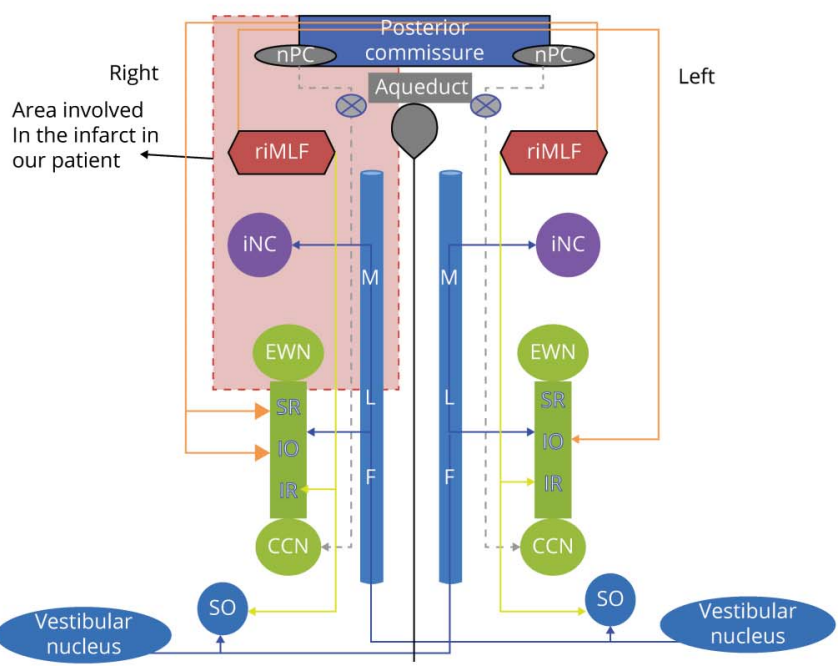

(A) Vertical gaze centers, their functions, and connections. (B) Area affected by infarct in our case. CCN = central caudal nucleus; EWN = Edinger Westphal nucleus; iNC = interstitial nucleus of Cajal; $I O=$ inferior oblique; IR = inferior rectus; $\mathrm{nPC}=$ nucleus of the posterior commissure; riMLF = rostral interstitial nucleus of the medial longitudinal fasciculus; $\mathrm{SO}=$ superior oblique; $\mathrm{SR}=$ superior rectus. 
Table 1 Summary of Centers Controlling Vertical Gaze ${ }^{4}$

\begin{tabular}{|c|c|c|c|c|}
\hline Structure & $\begin{array}{l}\text { Location (all at the } \\
\text { thalamo-mesencephalic } \\
\text { junction) }\end{array}$ & Connections & Function & Lesion \\
\hline riMLF & $\begin{array}{l}\text { Rostral to the oculomotor } \\
\text { nucleus and dorsomedial } \\
\text { to the red nucleus }\end{array}$ & $\begin{array}{l}\text { Supplies elevator muscles (SR } \\
\text { and IO) on both sides, but } \\
\text { depressor muscles (IR and SO) } \\
\text { only on the same side }\end{array}$ & Vertical saccades & $\begin{array}{l}\text { A unilateral lesion would affect the } \\
\text { ispilateral downward saccade }\end{array}$ \\
\hline INC & $\begin{array}{l}\text { Caudal to riMLF and close } \\
\text { to the rostral end of the } \\
\text { EWN and separated from } \\
\text { the oculomotor nuclei by } \\
\text { the MLF }\end{array}$ & $\begin{array}{l}\text { Vestibular nuclei, ipsilateral and } \\
\text { contralateral riMLF, and } \\
\text { contralateral INC }\end{array}$ & $\begin{array}{l}\text { Controls all } \\
\text { vertical eye } \\
\text { movements } \\
\text { except saccades }\end{array}$ & $\begin{array}{l}\text { Unilateral INC lesion produces an } \\
\text { ocular tilt reaction with torsional } \\
\text { vertical nystagmus; bilateral INC } \\
\text { lesions affect all vertical gaze } \\
\text { movements and may cause upbeat } \\
\text { nystagmus }\end{array}$ \\
\hline $\begin{array}{l}\text { PC consists of } \\
\text { crossing fibers } \\
\text { intermingled with } \\
\text { scattered cells that } \\
\text { constitute the nPC }\end{array}$ & $\begin{array}{l}\text { Rostral to the superior } \\
\text { colliculi at the junction of } \\
\text { the aqueduct and third } \\
\text { ventricle }\end{array}$ & $\begin{array}{l}\text { Connects INC to the oculomotor } \\
\text { nuclei and INC on the opposite } \\
\text { side, and fibers that connect nPC } \\
\text { with the contralateral INC and } \\
\text { riMLF }\end{array}$ & $\begin{array}{l}\text { Involved with all } \\
\text { vertical eye } \\
\text { movements, } \\
\text { especially upward } \\
\text { eye movement }\end{array}$ & $\begin{array}{l}\text { A single lesion at the PC can lead to } \\
\text { bilateral upgaze palsy because the } \\
\text { upgaze fibers cross at the level of the } \\
\text { PC }\end{array}$ \\
\hline
\end{tabular}

Abbreviations: EWN = Edinger Westphal nucleus; IO = inferior oblique; IR = inferior rectus; INC = interstitial nucleus of Cajal; MLF = medial longitudinal fasciculus; $\mathrm{nPC}=$ nucleus of the posterior commissure; PC = posterior commissure; riMLF = rostral interstitial nucleus of the medial longitudinal fasciculus; SO = superior oblique; $\mathrm{SR}=$ superior rectus.

the riMLF and INC would lead to loss of smooth pursuits, saccades, and VOR and a vertical and torsional nystagmus with fast component to the opposite side (figure $3 \mathrm{~B}) .^{5}$

The unpaired levator palpebrae superioris (LPS) subnucleus supplies the LPS on both sides and is situated caudally in the dorsal midbrain, hence it is also called the central caudal nucleus (CCN). It is postulated to receive inhibitory inputs from the nucleus of the PC. In case of an infarct involving the $\mathrm{PC}$, the inhibitory inputs to the $\mathrm{CCN}$ are reduced, leading to additional resting innervation going to the LPS on both sides causing bilateral upper eyelid retraction, as seen in our case. ${ }^{6}$ The fixed and dilated pupil can be explained by involvement of Edinger Westphal nucleus, which is situated in close proximity to riMLF and INC.

When present, dissociated convergence (i.e., ability to converge in absence of adduction) is a useful sign to differentiate internuclear ophthalmoplegia (INO) from myasthenia gravis and oculomotor nerve palsy. Based on presence or absence of convergence, Cogan described anterior and posterior types of INO. If a patient with INO is able to converge, despite inability to adduct, the medial longitudinal fasciculus (MLF) lesion is likely to be caudal, sparing medial rectus subnucleus of oculomotor nerve, and this is called posterior INO of Cogan. A more rostral lesion at the thalamo-mesencephalic junction, where nuclei

Table 2 Summary of Clinical Manifestations and Explanation

\begin{tabular}{ll}
\hline Manifestation & Explanation \\
\hline Bilateral complete upgaze palsy & Lesion at posterior commissure \\
\hline Unilateral downgaze palsy on right side & Lesion at the right riMLF \\
\hline Left eye hypotropia & Intact left riMLF causing unopposed downgaze movement \\
\hline $\begin{array}{l}\text { Downbeat torsional nystagmus with } \\
\text { torsional component to left }\end{array}$ & Combined involvement of right riMLF and INC \\
\hline $\begin{array}{l}\text { Downbeat nystagmus more pronounced in } \\
\text { left eye }\end{array}$ & Intact downgaze on left side due to intact left riMLF \\
\hline \begin{tabular}{l} 
Absent convergence \\
\hline Right INO
\end{tabular} & Involvement of convergence center situated at the tectum-pretectum level \\
\hline Bilateral eyelid retraction & $\begin{array}{l}\text { Involvement of riMLF at the level of rostral midbrain (as suggested by absent convergence) and involving } \\
\text { the adjacent paramedian tracts to and from the flocculus (as suggested by the gaze-evoked nystagmus) }\end{array}$ \\
\hline Fixed dilated pupil in right eye & Disinhibition of CCN from inhibitory impulse coming from nPC \\
\hline
\end{tabular}

Abbreviations: $\mathrm{CCN}=$ central caudal nucleus; $\mathrm{EWN}=$ Edinger Westphal nucleus; INC = interstitial nucleus of Cajal; $\mathrm{nPC}=$ nucleus of the posterior commissure; riMLF $=$ rostral interstitial nucleus of the medial longitudinal fasciculus. 
mediating convergence reside, is likely to affect convergence and this is called as anterior INO of Cogan, as seen in our case. Thus the presence or absence of convergence helps differentiate site of lesion in INO, though this rule is not always reliable. ${ }^{7}$ Usually in INO there is nystagmus in the abducting eye, but our patient had right-beating nystagmus on right gaze and left-beating on left gaze. This could be a form of gaze-evoked nystagmus, which is known to be caused by lesions of the MLF involving the adjacent paramedian tracts to and from the flocculus. ${ }^{7}$

Based on this information and the CT scan, table 2 summaries clinical features of the patient along with possible explanations for the same.

\section{Discussion}

One limitation while managing this case is lack of availability of MRI, due to which the exact extent of infarct cannot be known. That is a limitation that we need to live with while working in low-resource settings like sub-Saharan Africa. Though the resolution of images was not comparable to MRI, it was still possible to perform neuro-radiologic correlation of complex oculomotor manifestations.

Apart from rostral midbrain, our case also had involvement of medial part of right thalamus, which can also contribute to bilateral upgaze palsy. It may be attributed to interruption of the frontobulbar fibers that decussate in the medial nucleus of the thalamus, before reaching the superior colliculus. ${ }^{8}$

A thalamo-mesencephalic stroke can present with oculomotor manifestations alone, as in this case. Our patient had vertical one and a half syndrome with ispilateral internuclear ophthalmoplegia. We call it vertical one and half with horizontal half syndrome.

\section{Study Funding}

Supported by Hyderabad Eye Institute and Hyderabad Eye Research Foundation, India.

\section{Disclosure}

The authors report no disclosures relevant to the manuscript. Go to Neurology.org/ $\mathrm{N}$ for full disclosures.

\section{Appendix Authors}

\begin{tabular}{|c|c|c|}
\hline Name & Location & Contribution \\
\hline $\begin{array}{l}\text { Niranjan } \\
\text { Pehere, } \\
\text { DNB, FICO } \\
\text { (Hon) }\end{array}$ & $\begin{array}{l}\text { Liberia Eye Center, LV } \\
\text { Prasad Eye Institute, John } \\
\text { F. Kennedy Memorial } \\
\text { Medical Center, Monrovia, } \\
\text { Liberia }\end{array}$ & $\begin{array}{l}\text { Conceptualization of study } \\
\text { and study design, data } \\
\text { collection and data } \\
\text { analysis, drafting the } \\
\text { manuscript, editing the } \\
\text { manuscript }\end{array}$ \\
\hline $\begin{array}{l}\text { Kebede } \\
\text { Gofer, MD }\end{array}$ & $\begin{array}{l}\text { Consultant radiologist, } \\
\text { John F. Kennedy Memorial } \\
\text { Medical Center, Monrovia, } \\
\text { Liberia }\end{array}$ & $\begin{array}{l}\text { Data collection and data } \\
\text { analysis, editing the } \\
\text { manuscript }\end{array}$ \\
\hline
\end{tabular}

\section{References}

1. Danchaivijitr C, Kennard C. Diplopia and eye movement disorders. J Neurol Neurosurg Psychiatry 2004;75(suppl 4):iv24-iv31.

2. Puckett E, Almarzouqi SJ, Morgan ML, Lee AG. Doll's head maneuver/phenomenon, in horizontal gaze palsy. In: Schmidt-Erfurth U, Kohnen T, eds. Encyclopedia of Ophthalmology. Berlin: Springer; 2015

3. Sato K, Takahashi Y, Matsumoto N, et al. Rare valiant vertical one-and-a-half syndrome without ipsilateral upward gaze palsy in a patient with thalamomesencephalic stroke. Neurol Clin Neurosci 2018;6:133-135.

4. Wong AM. Understanding skew deviation and a new clinical test to differentiate it from trochlear nerve palsy. J AAPOS 2010;14:61-67.

5. Bhidayasiri R, Plant GT, Leigh RJ. A hypothetical scheme for the brainstem control of vertical gaze. Neurology 2000;54:1985-1993.

6. Averbuch-Heller L. Neurology of the eyelids. Curr Opin Ophthalmol 1997;8: 27-34.

7. Virgo JD, Plant GT. Internuclear ophthalmoplegia. Pract Neurol 2017;17: $149-153$.

8. Surapaneni K, Ferguson L, Altschuler EL. Why can't this patient look up? Bilateral vertical gaze palsy. PM R 2015;7:1306-1308.

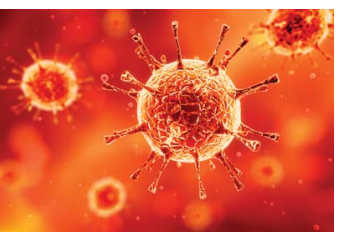

\section{COVID-19 and Neurologic Disease: Call for Papers!}

The editors of Neurology are interested in papers that address the neurological aspects of COVID-19 infection and challenges to the management of patients with chronic neurological conditions who have, or are at risk for, the infection. Relevant papers that pass initial internal review will undergo expedited peer review and online publication. We will consider papers posted in preprint servers.

Submit observational studies and clinical trials as Articles and case series and case reports under the Clinical/Scientific Notes category to https://submit.neurology.org/ today! 


\section{Neurology}

\section{Clinical Reasoning: A 48-Year-Old Man Presenting With Diplopia Niranjan K. Pehere and Kebede Gofer \\ Neurology 2021;96;399-405 Published Online before print November 16, 2020 \\ DOI 10.1212/WNL.0000000000011007}

This information is current as of November 16, 2020

Updated Information \& Services

References

Subspecialty Collections

Permissions \& Licensing

Reprints including high resolution figures, can be found at: http://n.neurology.org/content/96/8/399.full

This article cites 7 articles, 3 of which you can access for free at: http://n.neurology.org/content/96/8/399.full\#ref-list-1

This article, along with others on similar topics, appears in the following collection(s):

All global neurology

http://n.neurology.org/cgi/collection/all_global_neurology Diplopia (double vision)

http://n.neurology.org/cgi/collection/diplopia_double_vision Ocular motility

http://n.neurology.org/cgi/collection/ocular_motility

Pupils

http://n.neurology.org/cgi/collection/pupils

Stroke in young adults

http://n.neurology.org/cgi/collection/stroke_in_young_adults

Information about reproducing this article in parts (figures,tables) or in its entirety can be found online at:

http://www.neurology.org/about/about_the_journal\#permissions

Information about ordering reprints can be found online:

http://n.neurology.org/subscribers/advertise

Neurology ${ }^{\circledR}$ is the official journal of the American Academy of Neurology. Published continuously since 1951, it is now a weekly with 48 issues per year. Copyright () 2020 American Academy of Neurology. All rights reserved. Print ISSN: 0028-3878. Online ISSN: 1526-632X.

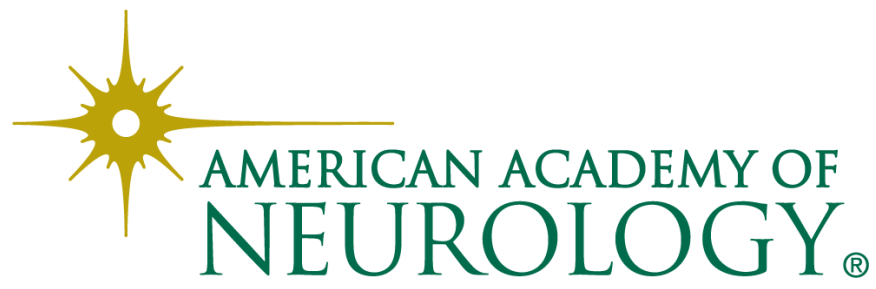

